\title{
DETERMINING THE IMPACT OF DIRECTIONALITY ON ROAD MARKINGS RETROREFLECTIVITY USING DYNAMIC METHOD
}

\author{
Dario BABIĆ*, Anđelko ŠČUKANEC, Darko BABIĆ \\ Dept of Traffic Signalling, Faculty of Transport and Traffic Sciences, University of Zagreb, Croatia
}

Received 21 March 2016; revised 14 October 2016; accepted 3 December 2016;

first published online 4 September 2017

\begin{abstract}
Road markings are an important component of delineation, intended to provide guidance and warning, to manage and regulate road traffic. In order to properly fulfil their function, road markings must be visible and it is precisely the visibility, in terms of road safety, that presents their most important characteristic. Practical tests showed that the marking visibility, or retroreflectivity, changes depending on directionality, showing higher values in the direction the marking is applied than in the opposite direction. This paper addressed the impact of road markings directionality on their retroreflectivity using the dynamic method for testing retroreflectivity. The research considered paint, thermoplastic and structural markings made of cold plastic. The results showed that the impact of directionality of paint and flat thermoplastic markings on their retroreflectivity is negligible. The average difference in retroreflectivity of renewed paint markings is $13.1 \mathrm{mcd} / \mathrm{m}^{2} \cdot \mathrm{lx}$ and $11.85 \mathrm{mcd} / \mathrm{m}^{2} \cdot \mathrm{lx}$ for existing paint markings, while the respective difference concerning flat thermoplastic markings is $9.60 \mathrm{mcd} / \mathrm{m}^{2} \cdot 1 \mathrm{x}$ for renewed markings and $9.20 \mathrm{mcd} / \mathrm{m}^{2} \cdot 1 \mathrm{x}$ for existing markings. A more significant difference was noted with structural markings made of cold plastic, namely $62.80 \mathrm{mcd} / \mathrm{m}^{2} \cdot \mathrm{lx}$ for renewed markings and $49.60 \mathrm{mcd} / \mathrm{m}^{2} \cdot \mathrm{lx}$ for existing markings. The results for paint and thermoplastic markings show that directionality should not be taken into consideration when evaluating their quality, which greatly facilitates and simplifies the process of testing the markings retroreflectivity. The stated results are of great importance for traffic safety and markings maintenance system.
\end{abstract}

Keywords: road markings, directionality, retroreflectivity, road markings materials, traffic safety, road markings management.

\section{Introduction}

As part of a traffic control plan, road markings warn, guide and inform road users and regulate road traffic using and combining lines, signs and symbols.

Materials used for road markings can be divided according to several criteria and it is very difficult to make a distinct division. The most common division is by type of material, according to which the markings are divided into: paint markings, thermoplastic markings, plural component systems, and preformed tapes. From an environmental point of view, the materials can be divided according to the presence and type of solvents into: solvent borne, waterborne, and solvent-free (Babić et al. 2015). Other criteria are associated with durability, chemical composition, retroreflective performance, etc.

In order to fulfil their function, the markings must be visible in all traffic and weather conditions. The visibility of markings is linked to their retroreflective performance (night-time visibility) and visibility of markings' colour (Zhang, Wu 2006).
During daytime, road users discern road markings mainly by the colour contrast between the marking and the road surface. In general, the perception of markings is not a problem when there is a sufficient amount of light. On the other hand, during the night or in conditions of low visibility, road users perceive markings based on their night-time visibility which is a function of the luminous contrast between the road markings and the road surface (Zhang et al. 2010). Luminous contrast is generally determined by the road marking retroreflectivity and it has a significantly greater importance for visibility, hence also for traffic safety, than colour contrast, given that the reaction time decreases with the increase of luminous contrast. (O'Donell et al. 2008).

Retroreflectivity is achieved by using glass beads embedded into road markings and is represented by the coefficient of retroreflected luminance $R_{L}$. According to the European Norm EN 1436:2009, the coefficient of retroreflected luminance is defined as the ratio of the

${ }^{*}$ Corresponding author. E-mail: dario.babic@fpz.hr 
output surface luminance $L$ and the input surface illuminance $E$, as shown by the following expression:

$$
R_{L}=\frac{L}{E} .
$$

Whereas, luminance is measured in candelas per square metre $\left[\mathrm{cd} / \mathrm{m}^{2}\right]$, and illuminance in lux $[\mathrm{lx}]$, so that the coefficient of retroreflected luminance is measured in candelas per lux per square meter $\left[\mathrm{cd} / \mathrm{m}^{2} \cdot \mathrm{lx}\right]$, or in a unit more suitable for road markings and used in this paper which is milicandela per lux per square meter $\left[\mathrm{mcd} / \mathrm{m}^{2} \cdot \mathrm{x}\right]$. It can be said that the coefficient of retroreflected luminance describes the potential of materials to restore light, during the day (creating a greater contrast), but also at night (creating a larger surface luminance) and depends on a number of factors, among which the most important are: the density of beads on the material surface, bead distribution on the marking surface, the relationship between the bead size and the thickness of the marking layer, the degree of embedment, adhesion of the marking material, environmental conditions, etc. (Ščukanec 2003).

In order to ensure a satisfactory level of road markings retroreflectivity, the markings need to be periodically tested and maintained. The main objective of testing is aimed at increasing the quality and durability of markings, and thus the general road safety while optimizing the costs of installation and maintenance.

Testing the road markings retroreflective performance comprises testing the daytime and/or night-time visibility and is conducted in two ways: static testing of road markings reflectivity (daytime and night-time visibility) and dynamic testing of road markings reflectivity (night-time visibility).

This paper examined the impact of road markings directionality on their retroreflectivity using the dynamic method for testing retroreflectivity. The research considered paint markings, thermoplastic markings and markings made of cold plastic.

\section{Overview of previous research and problem statement}

Previous research associated with road markings is mostly related to markings retroreflectivity. After researching the subjective evaluations of markings nighttime visibility, the authors (Graham et al. 1996; Loetterle et al. 2000; Parker, Meja 2003; Debaillon et al. 2007) suggest that the minimum retroreflectivity values should amount to: $100,120,150$ and $130-140 \mathrm{mcd} / \mathrm{m}^{2} \cdot 1 \mathrm{x}$.

In addition to the mentioned studies aimed at determining the minimum values of retroreflectivity in dry conditions, a number of studies was conducted to gain insight into the needs of the driver in wet and rainy night conditions (Gibbons, Williams 2012; Gibbons et al. 2007, 2012). Based on subjective evaluations of visibility of markings made of different materials under simulated wet conditions, the authors (Gibbons, Wil- liams 2012) propose $150 \mathrm{mcd} / \mathrm{m}^{2} \cdot \mathrm{lx}$ as a minimum value of retroreflectivity. The research results (Gibbons et al. 2007,2012 ) showed that tapes specially designed for wet conditions, as a road marking material, provide the best visibility and the greatest detection distance in mentioned conditions. Similar results have been obtained for thermoplastic materials, while paint demonstrated the worst results. The authors have also determined the existence of a log-linear relationship between the detection distance and retroreflectivity value.

Besides retroreflectivity, the basic parameter for comparison and evaluation of road marking quality is their service life or durability which has a direct influence on the visibility and the marking renewal schedule, and thus on the overall costs of maintenance. Over the past few decades, various authors have developed a number of models (regression, logarithmic, polynomial, neurofuzzy, etc.) to predict the durability of road markings (Andrady 1997; Lee et al. 1999; Migletz et al. 2001; Lindly, Wijesundera 2003; Kopf 2004; Craig et al. 2007; Sitzabee et al. 2009; Mull, Sitzabee 2012; Elwakil et al. 2014). Factors such as Average Annual Daily Traffic (AADT), initial retroreflectivity, material type and colour, road condition and position of the line on the road have been taken into consideration while developing the stated models.

The impact of paint road markings directionality on retroreflectivity was researched by Rasdorf et al. (2009). The hypothesis of this study was that glass beads have a horizontal velocity when sprayed from a pressurized dispenser, which causes more paint resin to cover one side of their surface than the other. An ideal paint application in which the glass beads are sprayed (or dropped) vertically into the paint resin is illustrated in Figure 1a, b. Alternatively, authors claim that Figure 1c, 1d show a more realistic painting scenario in which the glass beads have a horizontal velocity when they are sprayed from a moving truck traveling at a speed of $16 \ldots 9 \mathrm{~km} / \mathrm{h}$. This will cause more headlight to enter and be retroreflected back from the glass beads in one direction than in the other, resulting in different retroreflectivity values. a)

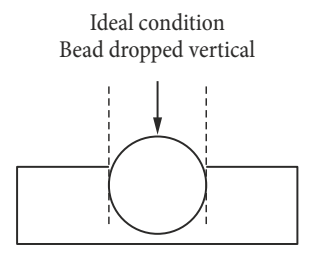

b)

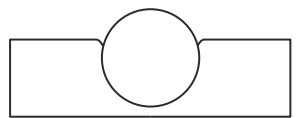

c)

$$
\text { Bead dropped at angle }
$$

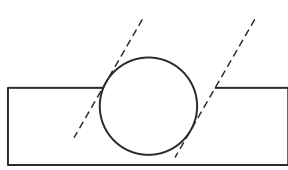

d)

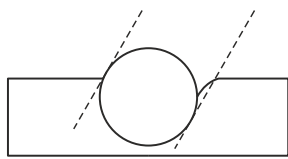

Figure 1. Different bead embedment illustration (Rasdorf et al. 2009) 
The study involved measuring yellow centreline marking retroreflectivity in both directions using handheld retroreflectormeter LTL 2000 (static method) on 40 roads. Test locations were selected randomly, and the marking directionality was unknown. Measuring was conducted in the period between 1 and 23 months after the markings had been applied, and a total of 20 measurements were taken in both directions at every location. Since the directionality was unknown, an additional test was carried out in which the centreline markings were measured on 6 roads several days after application and then again 4 months later. In this case, the marking directionality was known.

Based on the results, the authors concluded that there is a significant difference in the retroreflectivity of paint markings depending on directionality and that the stated difference can be as large as $66 \mathrm{mcd} / \mathrm{m}^{2} \cdot \mathrm{lx}$. The average difference in measurements on roads where the directionality was unknown is between 15 and 30\% greater in the direction the markings were applied than in the opposite direction. The analysis of the measurement results on roads where the directionality was known showed an even greater difference (as much as $50 \%$ higher values in the direction the markings were applied than in the opposite direction). The overall result is in the range of $20 \ldots 30 \mathrm{mcd} / \mathrm{m}^{2} \cdot \mathrm{lx}$ for older paint markings and $54 \ldots 74 \mathrm{mcd} / \mathrm{m}^{2} \cdot \mathrm{lx}$ for newer paint markings.

A similar research, intended to verify the stated phenomenon, was conducted by Sarasua et al. (2013). Yellow centrelines were examined in both directions and the results showed that, on average, waterborne markings exhibited $29.8 \%$ higher directional readings, while thermoplastic markings exhibited $9.6 \%$ higher directional readings.

The aim of this research is to examine the difference in road marking retroreflectivity depending on the directionality, using the dynamic method of testing road marking retroreflectivity. Moreover, the aim of the paper is also to expand the knowledge on the impact of directionality on the retroreflectivity of thermoplastic and cold plastic markings. It is important to note that in this research only white centrelines were examined, since according to Technical Regulations in the Republic of Croatia (Hrvatske ceste 2010) yellow lines are not used for permanent marking of roads.

\section{Data collection methods}

The data on road marking retroreflectivity used in this research were collected using a dynamic testing method which involves testing the retroreflectivity with a dynamic measuring device throughout their length. The measuring device is mounted on a vehicle and enables constant measuring of the coefficient of retroreflectivity $R_{L}$ while driving, by measuring the retroreflectivity of light ray of the tested surface at an angle of $2.29^{\circ}$, with an inlet angle of $1.24^{\circ}$ and at a distance of $30 \mathrm{~m}$, as shown in Figure 2.

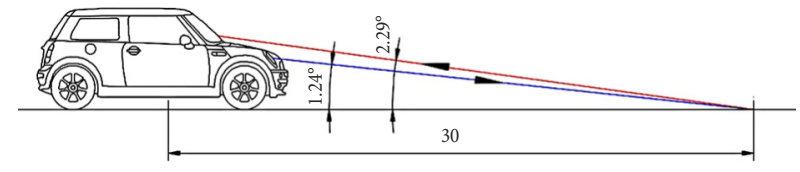

Figure 2. Illustration of the principle of night-time visibility measurement, illustration is not in scale (source: adapted by authors)

The data were collected by the Department of Traffic Signalling, Faculty of Transport and Traffic Sciences, University of Zagreb in 2014 and 2015 using Zehntner ZDR 6020 dynamic retroreflectometer (Zehntner 2009) mounted on the left side of the vehicle (given that only the centreline was measured) Mercedes-Benz Viano model. The dynamic device was calibrated prior to every test according to the calibration procedure prescribed by the manufacturer, and the measuring interval for all measurements was $50 \mathrm{~m}^{1}$. Since the measuring range of the used retroreflectometer is $\geq 1000 \times 880 \mathrm{~mm}$, the marking was measured per every centimetre. It is precisely the greater measuring range and greater amount of collected measurements that results in a more objective representation of the quality of retroreflectivity along the entire length of the road section and presents the main advantage of the dynamic testing method over the static method. When using the static method, the measurement results may vary if the examiner moves the instrument as much as a few centimetres, precisely because of the smaller measuring $\operatorname{area}^{2}$, which can ultimately result in an unrealistic evaluation of retroreflectivity quality.

An independent testing of the accuracy of Zehntner ZDR 6020 dynamic retroreflectometer confirmed that it is suitable for the dynamic measurement of road markings coefficient of retroreflection $R_{L}$, independent of velocity and it provides the same measuring results as a static retroreflectometer - Test Certificate No 09132009-05 (Zehntner 2009). In addition, the accuracy of calibration and measurement of Zehntner ZDR 6020 used in this research was verified with a handheld retroreflectometer Zehntner ZRM 6014 to assure the reliability of the measurement.

The research analysed the impact of directionality on the retroreflectivity of paint markings, thermoplastic markings and markings made of cold plastic. It is important to note that thermoplastic markings were performed as flat, while cold plastic markings were performed as structural.

The retroreflectivity data were collected on Croatian national roads located in different counties and constructed by various contractors using different equipment and machinery. The research involved only the white centrelines, and the directionality on every particular road was known in advance. The research com-

\footnotetext{
${ }^{1}$ Every $2 \mathrm{~ms}$ the device measures retroreflectivity and every $50 \mathrm{~m}$ reads the average retroreflectivity value of the respective interval;

2 Measuring area of static instruments depends on the manufacturer, but it is around $52 \times 218 \mathrm{~mm}$.
} 
prises 30 roads, of which 20 were painted, 5 were performed in thermoplastic and 5 in cold plastic. The total length of roads painted is $678 \mathrm{~km}$, roads with thermoplastic applied $30.8 \mathrm{~km}$ and cold plastic applied $25.8 \mathrm{~km}$. Retroreflectivity measurements for a particular road, in the direction the markings were applied and in the opposite direction, were taken on the same day, and the retroreflectivity data used in the analysis represent an average retroreflectivity value for all the measurements (all the 50 meter intervals) on the road.

The tests were divided into two stages. The first stage included testing the renewed markings in the period between 30 and 60 days after the markings had been applied in accordance with the applicable Technical Regulations in the Republic of Croatia (Hrvatske ceste 2010). The second stage included testing the markings on the same roads, but this time after a certain period of time when the markings were classified as the existing ones, according to the Technical Regulations (Hrvatske ceste 2010).

\section{Results}

The results of the conducted measurements have been divided into three parts according to materials used to make the markings. These results are presented in the following paragraphs.

\subsection{Paint markings}

Since the markings applied in paint are the most common in Croatia, a total of $678 \mathrm{~km}$ of paint markings was tested on 20 national roads throughout the country. The marking retroreflectivity was measured in the period between 30 and 60 days after the application, measuring the direction the markings were applied and the opposite direction for a particular road on the same day. Table 1 shows that the greatest difference in retroreflectivity is $27 \mathrm{mcd} / \mathrm{m}^{2} \cdot \mathrm{lx}$, while the smallest one is $4 \mathrm{mcd} / \mathrm{m}^{2} \cdot \mathrm{lx}$. The results indicate that the average absolute deviation of retroreflectivity is $13.1 \mathrm{mcd} / \mathrm{m}^{2} \cdot 1 \mathrm{x}$, which is negligible and can be attributed to an error of the dynamic retroreflectometer ${ }^{3}$.

The same centrelines on the same roads were measured again in the period between 200 and 300 days after the initial measurement. The measurements were taken in the identical way as the first time and the results are presented in Table 2 . The greatest difference in retroreflectivity of the existing markings is $21 \mathrm{mcd} / \mathrm{m}^{2} \cdot \mathrm{lx}$, while the smallest one is $5 \mathrm{mcd} / \mathrm{m}^{2} \cdot \mathrm{lx}$, which is almost identical to the results obtained with renewed markings. The average absolute difference in retroreflectivity of existing markings measured in the direction of application and the opposite direction is $11.85 \mathrm{mcd} / \mathrm{m}^{2} \cdot \mathrm{lx}$, which indicates the consistency of results. In addition, the results

Table 1. Results of retroreflectivity measurement in the direction of application and the opposite direction for renewed paint markings

\begin{tabular}{|c|c|c|c|c|c|c|c|}
\hline \multirow{2}{*}{$\begin{array}{l}\text { Road } \\
\text { No }\end{array}$} & \multirow{2}{*}{$\begin{array}{l}\text { Measuring } \\
\text { date }\end{array}$} & \multirow{2}{*}{$\begin{array}{l}\text { Days since } \\
\text { application }\end{array}$} & \multirow{2}{*}{$\begin{array}{l}\text { Measured } \\
\text { length }[\mathrm{km}]\end{array}$} & \multicolumn{2}{|c|}{$\begin{array}{c}\text { Average retroreflectivity } \\
{\left[\mathrm{mcd} / \mathrm{m}^{2} \cdot \mathrm{lx}\right]}\end{array}$} & \multirow{2}{*}{$\begin{array}{c}\text { Difference } \\
{\left[\mathrm{mcd} / \mathrm{m}^{2} \cdot \mathrm{lx}\right]}\end{array}$} & \multirow{2}{*}{$\begin{array}{l}\text { Absolute difference } \\
{\left[\mathrm{mcd} / \mathrm{m}^{2} \cdot \mathrm{lx}\right]}\end{array}$} \\
\hline & & & & direction & opposite & & \\
\hline 1 & $19 / 09 / 2014$ & 37 & 24.00 & 249 & 270 & -21 & 21 \\
\hline 2 & $10 / 09 / 2014$ & 42 & 32.00 & 174 & 164 & 10 & 10 \\
\hline 3 & $08 / 09 / 2014$ & 46 & 8.00 & 282 & 286 & -4 & 4 \\
\hline 4 & $08 / 09 / 2014$ & 46 & 5.00 & 362 & 385 & -23 & 23 \\
\hline 5 & $08 / 09 / 2014$ & 44 & 9.00 & 250 & 263 & -13 & 13 \\
\hline 6 & $26 / 08 / 2014$ & 39 & 4.00 & 160 & 174 & -14 & 14 \\
\hline 7 & $25 / 08 / 2014$ & 51 & 6.00 & 285 & 276 & 9 & 9 \\
\hline 8 & $25 / 08 / 2014$ & 50 & 16.00 & 245 & 261 & -16 & 16 \\
\hline 9 & $18 / 07 / 2014$ & 33 & 47.00 & 357 & 330 & 27 & 27 \\
\hline 10 & $06 / 07 / 2014$ & 45 & 134.00 & 292 & 297 & -5 & 5 \\
\hline 11 & $09 / 05 / 2014$ & 32 & 7.00 & 294 & 290 & 4 & 4 \\
\hline 12 & $04 / 07 / 2014$ & 52 & 27.00 & 336 & 325 & 11 & 11 \\
\hline 13 & $04 / 07 / 2014$ & 55 & 90.00 & 324 & 318 & 6 & 6 \\
\hline 14 & $19 / 09 / 2014$ & 36 & 6.00 & 289 & 277 & 12 & 12 \\
\hline 15 & $19 / 09 / 2014$ & 37 & 30.00 & 264 & 279 & -15 & 15 \\
\hline 16 & $18 / 07 / 2014$ & 35 & 31.00 & 291 & 274 & 17 & 17 \\
\hline 17 & $19 / 09 / 2014$ & 40 & 56.00 & 252 & 261 & -9 & 9 \\
\hline 18 & $18 / 09 / 2014$ & 44 & 38.00 & 271 & 259 & 12 & 12 \\
\hline 19 & $04 / 07 / 2014$ & 40 & 86.00 & 298 & 285 & 13 & 13 \\
\hline 20 & $06 / 07 / 2014$ & 42 & 22.00 & 386 & 365 & 21 & 21 \\
\hline \multicolumn{3}{|c|}{ Average } & 678.00 & 283.05 & 281.95 & - & 13.10 \\
\hline
\end{tabular}

$\overline{3}$ According to Zehntner's Test Certificate, error of dynamic retroreflectometer Zehntner ZDR 6020 is at most +(3.5...5.3)\%. 
Table 2. Results of retroreflectivity measurement in the direction of application and the opposite direction for existing paint markings

\begin{tabular}{|c|c|c|c|c|c|c|c|}
\hline \multirow{2}{*}{$\begin{array}{c}\text { Road } \\
\text { No }\end{array}$} & \multirow{2}{*}{$\begin{array}{l}\text { Measuring } \\
\text { date }\end{array}$} & \multirow{2}{*}{$\begin{array}{l}\text { Days from } \\
\text { the first } \\
\text { measurement }\end{array}$} & \multirow{2}{*}{$\begin{array}{l}\text { Measured } \\
\text { length }[\mathrm{km}]\end{array}$} & \multicolumn{2}{|c|}{$\begin{array}{l}\text { Average retroreflectivity } \\
{\left[\mathrm{mcd} / \mathrm{m}^{2} \cdot \mathrm{lx}\right]}\end{array}$} & \multirow{2}{*}{$\begin{array}{c}\text { Difference } \\
{\left[\mathrm{mcd} / \mathrm{m}^{2} \cdot \mathrm{lx}\right]}\end{array}$} & \multirow{2}{*}{$\begin{array}{l}\text { Absolute difference } \\
{\left[\quad\left[\mathrm{mcd} / \mathrm{m}^{2} \cdot \mathrm{lx}\right]\right.}\end{array}$} \\
\hline & & & & direction & opposite & & \\
\hline 1 & $15 / 04 / 2015$ & 208 & 24.00 & 113 & 129 & -16 & 16 \\
\hline 2 & $05 / 05 / 2015$ & 237 & 32.00 & 74 & 69 & 5 & 5 \\
\hline 3 & $22 / 04 / 2015$ & 226 & 8.00 & 174 & 160 & 14 & 14 \\
\hline 4 & $22 / 04 / 2015$ & 226 & 5.00 & 226 & 242 & -16 & 16 \\
\hline 5 & $22 / 04 / 2015$ & 226 & 9.00 & 146 & 139 & 7 & 7 \\
\hline 6 & $04 / 05 / 2015$ & 251 & 4.00 & 61 & 50 & 11 & 11 \\
\hline 7 & $27 / 04 / 2015$ & 245 & 6.00 & 121 & 114 & 7 & 7 \\
\hline 8 & $27 / 04 / 2015$ & 245 & 16.00 & 99 & 111 & -12 & 12 \\
\hline 9 & $29 / 03 / 2015$ & 254 & 47.00 & 174 & 156 & 18 & 18 \\
\hline 10 & $24 / 03 / 2015$ & 261 & 134.00 & 145 & 151 & -6 & 6 \\
\hline 11 & $02 / 04 / 2015$ & 328 & 7.00 & 160 & 169 & -9 & 9 \\
\hline 12 & $07 / 04 / 2015$ & 277 & 27.00 & 231 & 224 & 7 & 7 \\
\hline 13 & $07 / 04 / 2015$ & 277 & 90.00 & 163 & 157 & 6 & 6 \\
\hline 14 & $02 / 05 / 2015$ & 225 & 6.00 & 137 & 129 & 8 & 8 \\
\hline 15 & $02 / 05 / 2015$ & 225 & 30.00 & 122 & 141 & -19 & 19 \\
\hline 16 & $02 / 05 / 2015$ & 288 & 31.00 & 141 & 129 & 12 & 12 \\
\hline 17 & $02 / 05 / 2015$ & 225 & 56.00 & 116 & 101 & 15 & 15 \\
\hline 18 & $03 / 05 / 2015$ & 227 & 38.00 & 139 & 118 & 21 & 21 \\
\hline 19 & $02 / 05 / 2015$ & 302 & 86.00 & 165 & 178 & -13 & 13 \\
\hline 20 & $26 / 03 / 2015$ & 263 & 22.00 & 241 & 226 & 15 & 15 \\
\hline \multicolumn{3}{|c|}{ Average } & 678.00 & 147.40 & 144.65 & - & 11.85 \\
\hline
\end{tabular}

demonstrate that the difference in retroreflectivity measured in the direction the markings were applied and in the opposite direction insignificantly changes over time.

\subsection{Thermoplastic markings}

Given that thermoplastic markings are relatively poorly represented on the Croatian roads, the amount of data was limited and only 5 roads were examined in total length of $30.80 \mathrm{~km}$. The testing procedure was identical to the one used with paint markings, and only flat thermoplastic markings were tested.

Table 3 presents the results of retroreflectivity measurements in the direction of application and the opposite direction for thermoplastic markings in renewed condition, that is, in the period between 30 and 60 days after the application. The results indicate that the average absolute difference in retroreflectivity measured in the direction the renewed thermoplastic markings were applied and in the opposite direction is $9.60 \mathrm{mcd} / \mathrm{m}^{2} \cdot 1 \mathrm{x}$. The stated difference, as with paint markings, is negligible and can be attributed to an error by the dynamic retroreflectometer.

Measurements of the existing markings were taken after 200 days. Exceptionally, on two roads the measurements were taken after 500 days. Table 4 shows that the difference between the retroreflectivity in the direction of application and in the opposite direction for the existing thermoplastic markings is the same as in the initial measurement, and the average absolute difference is $9.20 \mathrm{mcd} / \mathrm{m}^{2} \cdot 1 \mathrm{x}$.

Table 3. Results of retroreflectivity measurement in the direction of application and the opposite direction for renewed thermoplastic markings

\begin{tabular}{|c|c|c|c|c|c|c|c|}
\hline \multirow{2}{*}{$\begin{array}{l}\text { Road } \\
\text { No }\end{array}$} & \multirow{2}{*}{$\begin{array}{l}\text { Measuring } \\
\text { date }\end{array}$} & \multirow{2}{*}{$\begin{array}{l}\text { Days since } \\
\text { application }\end{array}$} & \multirow{2}{*}{$\begin{array}{l}\text { Measured } \\
\text { length }[\mathrm{km}]\end{array}$} & \multicolumn{2}{|c|}{$\begin{array}{l}\text { Average retroreflectivity } \\
\qquad\left[\mathrm{mcd} / \mathrm{m}^{2} \cdot \mathrm{x}\right]\end{array}$} & \multirow{2}{*}{$\begin{array}{l}\text { Difference } \\
{\left[\mathrm{mcd} / \mathrm{m}^{2} \cdot \mathrm{lx}\right]}\end{array}$} & \multirow{2}{*}{$\begin{array}{l}\text { Absolute difference } \\
{\left[\mathrm{mcd} / \mathrm{m}^{2} \cdot \mathrm{x}\right]}\end{array}$} \\
\hline & & & & direction & opposite & & \\
\hline 1 & $05 / 03 / 2014$ & 42 & 16.70 & 326 & 338 & -12 & 12 \\
\hline 2 & $06 / 04 / 2014$ & 34 & 6.30 & 317 & 309 & 8 & 8 \\
\hline 3 & $19 / 03 / 2015$ & 36 & 1.50 & 316 & 310 & 6 & 6 \\
\hline 4 & $29 / 03 / 2015$ & 40 & 1.30 & 327 & 319 & 8 & 8 \\
\hline 5 & $26 / 02 / 2015$ & 46 & 5.00 & 373 & 359 & 14 & 14 \\
\hline \multicolumn{3}{|c|}{ Average } & 30.80 & 331.80 & 327.00 & - & 9.60 \\
\hline
\end{tabular}


Table 4. Results of retroreflectivity measurement in the direction of application and the opposite direction for existing thermoplastic markings

\begin{tabular}{|c|c|c|c|c|c|c|c|}
\hline \multirow{2}{*}{$\begin{array}{c}\text { Road } \\
\text { No }\end{array}$} & \multirow{2}{*}{$\begin{array}{l}\text { Measuring } \\
\text { date }\end{array}$} & \multirow{2}{*}{$\begin{array}{l}\text { Days from the first } \\
\text { measurement }\end{array}$} & \multirow{2}{*}{$\begin{array}{c}\text { Measured length } \\
{[\mathrm{km}]}\end{array}$} & \multicolumn{2}{|c|}{$\begin{array}{l}\text { Average retroreflectivity } \\
{\left[\mathrm{mcd} / \mathrm{m}^{2} \cdot \mathrm{lx}\right]}\end{array}$} & \multirow{2}{*}{$\begin{array}{l}\text { Difference } \\
{\left[\mathrm{mcd} / \mathrm{m}^{2} \cdot \mathrm{lx}\right]}\end{array}$} & \multirow{2}{*}{$\begin{array}{l}\text { Absolute difference } \\
\qquad\left[\mathrm{mcd} / \mathrm{m}^{2} \cdot \mathrm{lx}\right]\end{array}$} \\
\hline & & & & direction & opposite & & \\
\hline 1 & $11 / 09 / 2015$ & 555 & 16.70 & 139 & 139 & 0 & 0 \\
\hline 2 & $05 / 10 / 2015$ & 547 & 6.30 & 146 & 159 & -13 & 13 \\
\hline 3 & $13 / 11 / 2015$ & 239 & 1.50 & 159 & 146 & 13 & 13 \\
\hline 4 & $13 / 11 / 2015$ & 229 & 1.30 & 151 & 142 & 9 & 9 \\
\hline 5 & $18 / 11 / 2015$ & 265 & 5.00 & 289 & 278 & 11 & 11 \\
\hline \multicolumn{3}{|c|}{ Average } & 30.80 & 176.80 & 172.80 & - & 9.20 \\
\hline
\end{tabular}

\subsection{Cold Plastic Markings}

In addition to thermoplastic markings, as previously stated, the research also included 5 roads with cold plastic structural markings. The total length of the respective roads is $25.80 \mathrm{~km}$. The testing procedure was the same as in the previous two cases.

Table 5 shows the results of retroreflectivity testing in the direction of application and in the opposite direction for structural markings made of cold plastic in a renewed condition, that is, in the period between 30 and 60 days after application. The average absolute difference in retroreflectivity is in this case significant and amounts to $62.80 \mathrm{mcd} / \mathrm{m}^{2} \cdot \mathrm{lx}$. Also, the results show that in some cases the retroreflectivity in the direction of application is higher than in the opposite direction, while in other cases it is vice-versa, and such differences can amount to as much as $133 \mathrm{mcd} / \mathrm{m}^{2} \cdot \mathrm{lx}$.
Table 6 presents test results for markings made of cold plastic in the period between 100 and 500 days. The results, same as with renewed cold plastic markings, indicate a significant difference in retroreflectivity, whose average absolute difference amounts to $49.60 \mathrm{mcd} / \mathrm{m}^{2} \cdot \mathrm{lx}$. Even though the differences are somewhat smaller with respect to the initial measurement, it can be concluded that the difference is maintained over time. On top of that, in some cases the retroreflectivity in the direction of application is higher than in the opposite direction, while in other cases it is vice-versa.

Significant differences in retroreflectivity in the direction of application and in the opposite direction occur due to the marking structure. As shown in Figure 3, the tested structural markings consist of a number of irregular 'bumps' containing glass beads. Due to irregular structure of the 'bumps', during application the glass

Table 5. Results of retroreflectivity measurement in the direction of application and the opposite direction for renewed structural markings made of cold plastic

\begin{tabular}{|c|c|c|c|c|c|c|c|}
\hline \multirow{2}{*}{$\begin{array}{c}\text { Road } \\
\text { No }\end{array}$} & \multirow{2}{*}{$\begin{array}{l}\text { Measuring } \\
\text { date }\end{array}$} & \multirow{2}{*}{$\begin{array}{l}\text { Days since } \\
\text { application }\end{array}$} & \multirow{2}{*}{$\begin{array}{l}\text { Measured length } \\
{[\mathrm{km}]}\end{array}$} & \multicolumn{2}{|c|}{$\begin{array}{l}\text { Average retroreflectivity } \\
{\left[\mathrm{mcd} / \mathrm{m}^{2} \cdot \mathrm{lx}\right]}\end{array}$} & \multirow{2}{*}{$\begin{array}{l}\text { Difference } \\
{\left[\mathrm{mcd} / \mathrm{m}^{2} \cdot \mathrm{lx}\right]}\end{array}$} & \multirow{2}{*}{$\begin{array}{l}\text { Absolute difference } \\
\qquad\left[\mathrm{mcd} / \mathrm{m}^{2} \cdot \mathrm{lx}\right]\end{array}$} \\
\hline & & & & direction & opposite & & \\
\hline 1 & $06 / 10 / 2014$ & 45 & 12.00 & 578 & 546 & 32 & 32 \\
\hline 2 & $04 / 05 / 2014$ & 37 & 7.00 & 527 & 583 & -56 & 56 \\
\hline 3 & $31 / 10 / 2014$ & 39 & 1.00 & 589 & 621 & -32 & 32 \\
\hline 4 & $09 / 09 / 2014$ & 41 & 5.00 & 443 & 504 & -61 & 61 \\
\hline 5 & $05 / 07 / 2015$ & 49 & 0.80 & 587 & 454 & 133 & 133 \\
\hline \multicolumn{3}{|c|}{ Average } & 25.80 & 544.80 & 541.60 & - & 62.80 \\
\hline
\end{tabular}

Table 6. Results of retroreflectivity measurement in the direction of application and the opposite direction for existing structural markings made of cold plastic

\begin{tabular}{|c|c|c|c|c|c|c|c|}
\hline \multirow{2}{*}{$\begin{array}{c}\text { Road } \\
\text { No }\end{array}$} & \multirow{2}{*}{$\begin{array}{l}\text { Measuring } \\
\text { date }\end{array}$} & \multirow{2}{*}{$\begin{array}{l}\text { Days from the first } \\
\text { measurement }\end{array}$} & \multirow{2}{*}{$\begin{array}{l}\text { Measured length } \\
{[\mathrm{km}]}\end{array}$} & \multicolumn{2}{|c|}{$\begin{array}{l}\text { Average retroreflectivity } \\
{\left[\mathrm{mcd} / \mathrm{m}^{2} \cdot \mathrm{lx}\right]}\end{array}$} & \multirow{2}{*}{$\begin{array}{l}\text { Difference } \\
{\left[\mathrm{mcd} / \mathrm{m}^{2} \cdot \mathrm{lx}\right]}\end{array}$} & \multirow{2}{*}{$\begin{array}{l}\text { Absolute difference } \\
{\left[\mathrm{mcd} / \mathrm{m}^{2} \cdot \mathrm{lx}\right]}\end{array}$} \\
\hline & & & & direction & opposite & & \\
\hline 1 & $08 / 09 / 2015$ & 337 & 12.00 & 378 & 353 & 25 & 25 \\
\hline 2 & $08 / 09 / 2015$ & 492 & 7.00 & 297 & 358 & -61 & 61 \\
\hline 3 & $27 / 09 / 2015$ & 331 & 1.00 & 362 & 388 & -26 & 26 \\
\hline 4 & $27 / 09 / 2014$ & 383 & 5.00 & 348 & 391 & -43 & 43 \\
\hline 5 & $13 / 11 / 2015$ & 131 & 0.80 & 584 & 491 & 93 & 93 \\
\hline \multicolumn{3}{|c|}{ Average } & 25.80 & 393.80 & 396.20 & - & 49.60 \\
\hline
\end{tabular}




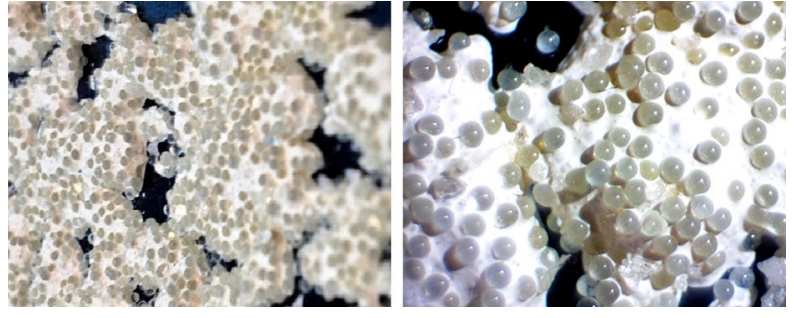

Figure 3. Illustration of a cold plastic structural marking (laboratory sample)

beads fall on all sides of the marking structure, which makes it possible to sometimes have more beads in the direction of application and other times in the opposite direction, resulting in a difference in retroreflectivity.

\section{Conclusions}

The results of the conducted research show that the difference in retroreflectivity of paint white centrelines measured in the direction of application and in the opposite direction is negligible and pertains to the domain of dynamic device error. Measurements were taken in two stages. In the first stage, the markings were measured in the period between 30 and 60 days after the application - in accordance with the Technical Regulations in the Republic of Croatia (Hrvatske ceste 2010), while the second stage involved measuring the markings more than 200 days after the application.

The results also indicate consistency, given that the average absolute difference with the renewed (new) markings amounted to 13.10 , and for the existing markings (more than 200 days after the application) it was $11.85 \mathrm{mcd} / \mathrm{m}^{2} \cdot \mathrm{lx}$.

Generally, retroreflectivity is slightly higher in the direction of application than in the opposite direction. This can be explained by the fact that not all of the glass beads are sprayed vertically into the road marking material, as they have a horizontal velocity when sprayed from a pressurized dispenser, which can cause more paint covering one side of their surface than the other. With the improved application technology, as well as chemical coating around glass beads which allows road marking material to 'climb' to a certain extent on the glass bead, this difference in retroreflectivity for flat markings is negligible as results of this study show.

These results are in contradiction with the results of the studies (Rasdorf et al. 2009; Sarasua et al. 2013) which reported significant differences in road markings retroreflectivity depending on directionality. The authors in (Rasdorf et al. 2009; Sarasua et al. 2013) conducted their research using a handheld retroreflectometer, that is, the static method. The problem with the static method is a relatively small measuring range of the handheld retroreflectometer, so even a small displacement of the device on the marking may result in obtaining different retroreflectivity values. When examining the impact of directionality on retroreflectivity, the said problem can well affect the results because it is very difficult to set the device in the exact spot in both directions in order to obtain accurate results. On the other hand, the dynamic retroreflectometer measuring range takes into consideration the entire width and length of the markings, which ultimately provides more objective results of the measured marking retroreflectivity quality. Based on the quantity of measured kilometres and obtained results, it can be concluded that there is no difference in paint markings retroreflectivity measured in the direction of application and in the opposite direction.

The results concerning the impact of directionality on thermoplastic flat markings retroreflectivity show a similar negligible difference. The tests were conducted in the same manner as with paint markings, which means that the markings were initially tested in the period between 30 and 60 days and then after 200 days, with an exception of two roads that were examined after 500 days. The average absolute difference in retroreflectivity of thermoplastic flat markings in the direction of application and in the opposite direction is $9.60 \mathrm{mcd} / \mathrm{m}^{2} \cdot \mathrm{lx}$. The obtained results are consistent with the fact that thermoplastic materials have the same retroreflectivity directionality property as paint (Rasdorf et al. 2009).

However, the results for the structural cold plastic showed that the impact of directionality on the retroreflectivity is significant and that the difference between the direction of application and the opposite direction may even amount to more than $100 \mathrm{mcd} / \mathrm{m}^{2} \cdot \mathrm{lx}$. The average absolute difference on $25.8 \mathrm{~km}$ of examined markings is $62.80 \mathrm{mcd} / \mathrm{m}^{2} \cdot \mathrm{lx}$ for renewed markings and $49.60 \mathrm{mcd} / \mathrm{m}^{2} \cdot \mathrm{lx}$ for existing markings.

The above results may be explained as a consequence of the marking structure. Structural markings consist of a number of irregular 'bumps' containing glass beads. Due to irregular structure of the 'bumps', during application the glass beads fall on all sides of the marking structure, which makes it possible to sometimes have more beads in the direction of application and other times in the opposite direction, resulting in a difference in retroreflectivity.

In order to statistically validate the research results, a paired $t$-test was conducted for each material from the data provided in Tables 1-6. The null hypothesis indicates that the difference in arithmetic means of two groups of data, in this case the mean value of retroreflection in the direction of application (one data group) and in the opposite direction (second data group), is statistically insignificant. The alternative hypothesis presents a case with a statistically significant difference between the two groups of data. The hypothesized mean difference of the $t$-test was 0 and the significance level $\alpha$ was set at 0.05 .

As shown in Table 7, $p$-value for any of the three examined materials, regardless of the state of the marking, is higher than $\alpha$, which means that the null hypothesis is confirmed and that there is no statistically significant difference between retroreflectivity measured in the direction of application and in the opposite direction.

Therefore, the research clearly shows that the impact of directionality of paint and flat thermoplastic markings on their retroreflectivity is negligible and that 
directionality should not be taken into consideration for quality testing and evaluation of the respective markings, which greatly facilitates and simplifies the marking retroreflectivity testing procedure.

Table 7. $t$-test results

\begin{tabular}{|l|c|c|c|c|}
\hline \multirow{2}{*}{ Material } & \multirow{2}{*}{$\begin{array}{c}\text { State } \\
\text { of the } \\
\text { marking }\end{array}$} & \multicolumn{2}{|c|}{$\begin{array}{c}\text { Average } \\
\text { retroreflectivity } \\
{\left[\mathrm{mcd} / \mathrm{m}^{2} \cdot \mathrm{l}\right]}\end{array}$} & \multirow{2}{*}{-value } \\
\cline { 3 - 4 } & & direction & opposite & \\
\hline \multirow{2}{*}{ paint } & renewed & 283.05 & 281.95 & 0.94888 \\
\cline { 2 - 5 } & existing & 147.04 & 144.65 & 0.85738 \\
\hline \multirow{2}{*}{ thermoplastic } & renewed & 331.80 & 327.00 & 0.74440 \\
\cline { 2 - 5 } & existing & 176.80 & 172.80 & 0.92030 \\
\hline \multirow{2}{*}{ cold plastic } & renewed & 544.80 & 541.60 & 0.93881 \\
\cline { 2 - 5 } & existing & 393.80 & 396.20 & 0.96648 \\
\hline
\end{tabular}

Even though $t$-test does not result in a statistically significant difference, the absolute mean difference in retroreflectivity values depending on directionality is evident with structural markings made of cold plastic, amounting to $62.80 \mathrm{mcd} / \mathrm{m}^{2} \cdot \mathrm{lx}$ for renewed markings and $49.60 \mathrm{mcd} / \mathrm{m}^{2} \cdot \mathrm{lx}$ for existing markings.

As an extension of this paper, it is suggested to conduct a detailed research of the impact of directionality on structural marking retroreflectivity, both for thermoplastic and cold plastic markings. A more extensive research would provide a clear insight into the impact of directionality on structural marking retroreflectivity, which would result in a redefinition of protocols and methods for testing and evaluating the markings. Furthermore, investigating the impact of various structure design on the difference in retroreflectivity in the direction of application and the opposite direction would enable defining, from that point of view, an optimal structure.

\section{References}

Andrady, A. L. 1997. Pavement Marking Materials: Assessing Environment Friendly Performance. Washington, DC: National Academy Press. 66 p.

Babić, D.; Burghardt, T. E.; Babić, D. 2015. Application and characteristics of waterborne road marking paint, International Journal for Traffic and Transport Engineering 5(2): 150-169. https://doi.org/10.7708/ijtte.2015.5(2).06

Craig, W. N.; Sitzabee, W. E.; Rasdorf, W. J.; Hummer, J. E. 2007. Statistical validation of the effect of lateral line location on pavement marking retroreflectivity degradation, Public Works Management \& Policy 12(2): 431-450. https://doi.org/10.1177/1087724X07308773

Debaillon, C.; Carlson, P.; He, Y.; Schnell, T.; Aktan, F. 2007. Updates to Research on Recommended Minimum Levels for Pavement Marking Retroreflectivity to Meet Driver Night Visibility Needs. Report No. FHWA-HRT-07-059. US Department of Transportation. Federal, Highway Administration, McLean, VA, US. 50 p. Available from Internet: https://www.fhwa.dot.gov/publications/research/ safety/07059/07059.pdf
Elwakil, E.; Eweda, A.; Zayed, T. 2014. Modelling the effect of various factors on the condition of pavement marking, Structure and Infrastructure Engineering: Maintenance, Management, Life-Cycle Design and Performance 10(1): 93-105. https://doi.org/10.1080/15732479.2012.701650

EN 1436:2009. Road Marking Materials. Road Marking Performance for Road Users.

Gibbons, R. B.; Williams, B. M. 2012. Assessment of the Durability of Wet Night Visible Pavement Markings: Wet Visibility Project Phase IV. Report No VCTIR 12-R13. Virginia Center for Transportation Innovation and Research, US. 52 p. Available from Internet: http://www.virginiadot.org/ vtrc/main/online_reports/pdf/12-r13.pdf

Gibbons, R.; Williams, B.; Cottrell, B. 2012. Refinement of drivers' visibility needs during wet night conditions, Transportation Research Record: Journal of the Transportation Research Board 2272: 113-120. https://doi.org/10.3141/2272-13

Gibbons, R.; Williams, B.; Cottrell, B. 2007. Assessment of durability of wet night visible pavement markings: visibility experiment, Transportation Research Record: Journal of the Transportation Research Board 2337: 67-73.

https://doi.org/10.3141/2337-09

Graham, J.; Harrold, J.; King, L. 1996. Pavement marking retroreflectivity requirements for older drivers, Transportation Research Record: Journal of the Transportation Research Board 1529: 65-70. https://doi.org/10.3141/1529-08

Hrvatske ceste. 2010. Technical Terms of Company Croatian Roads Ltd. Hrvatske ceste d.o.o. Available from Internet: http://www.hrvatske-ceste.hr

Kopf, J. 2004. Reflectivity of Pavement Markings: Analysis of Retroreflectivity Degradation Curves. Report No WA-RD 592.1. Washington State Transportation Center (TRAC). $48 \mathrm{p}$.

Lee, J.-T.; Maleck, T. L.; Taylor, W. C. 1999. Pavement marking material evaluation study in Michigan, ITE Journal 69(7): $44-51$.

Lindly, J. K.; Wijesundera, R. K. 2003. Evaluation of Profiled Pavement Markings. UTCA Report Number 01465. University Transportation Center for Alabama (UCTA). 112 p. Available from Internet: https://ntl.bts.gov/lib/24000/24900 /24956/01465FnlRpt.pdf

Loetterle, F.; Beck, R.; Carlson, J. 2000. Public perception of pavement-marking brightness, Transportation Research Record: Journal of the Transportation Research Board 1715: 51-59. https://doi.org/10.3141/1715-08

Migletz, J.; Graham, J.; Harwood, D.; Bauer, K. 2001. Service life of durable pavement markings, Transportation Research Record: Journal of the Transportation Research Board 1749: 13-21. https://doi.org/10.3141/1749-03

Mull, D. M.; Sitzabee, W. E. 2012. Paint pavement marking performance prediction model, Journal of Transportation Engineering 138(5). https://doi.org/10.1061/(ASCE)TE.1943-5436.0000360

O’Donell, B. M.; Colombo, E. M. 2008. Simple reaction times to chromatic stimuli: luminance and chromatic contrast, Lighting Research \& Technology 40(4): 359-371. https://doi.org/10.1177/1477153508097709

Parker, N.; Meja, M. 2003. Evaluation of performance of permanent pavement markings, Transportation Research Record: Journal of the Transportation Research Board 1824: 123-132. https://doi.org/10.3141/1824-14 
Rasdorf, W. J.; Zhang, G.; Hummer, J. E. 2009. The impact of directionality on paint pavement marking retroreflectivity, Public Works Management \& Policy 13(3): 265-277. https://doi.org/10.1177/1087724X08330824

Sarasua, W. A.; Davis, W. J.; Robertson, J.; Johnson, J. A. 2013. A methodology for evaluating centerline markings in temperate climates, Journal of Transportation of the Institute of Transportation Engineers 5(1): 17-30.

Sitzabee, W. E.; Hummer, J. E.; Rasdorf, W. 2009. Pavement marking degradation modeling and analysis, Journal of Infrastructure Systems 15(3). https://doi.org/10.1061/(ASCE)1076-0342(2009)15:3(190)

Ščukanec, A. 2003. Primjena retroreflektirajućih materijala u funkciji cestovnoprometne sigurnosti: doktorska disertacija. Sveučilište u Zagrebu, Fakultet prometnih znanosti. 187 l. (in Croatian).

Zehntner. 2009. Translation of Test Certificate No. 0913-200905 of the Suitability of the Dynamic Retroreflectometer ZDR 6020 for the Dynamic Measurement of the Coefficient of Retroreflected Luminance $R_{L}$ of Road Markings. Zehntner $\mathrm{GmbH}$ Testing Instruments. 13 p. Available from Internet: http://www.zehntner.com/download/ZDR6020_test_report_StrausZert_e.pdf

Zhang, G.; Hummer, J. E.; Rasdorf, W. 2010. Impact of bead density on paint pavement marking retroreflectivity, Journal of Transportation Engineering 136(8).

https://doi.org/10.1061/(ASCE)TE.1943-5436.0000142

Zhang, Y.; Wu, D. 2006. Methodologies to predict service lives of pavement marking materials, Journal of the Transportation Research Forum 45(3): 5-18.

https://doi.org/10.5399/osu/jtrf.45.3.601 